\title{
O trabalho no complexo econômico industrial da saúde no Brasil: algumas evidências
}

\author{
Camila Lins Rodrigues (Unimontes); \\ Juliana Bacelar de Araújo (UFRN)
}

\begin{abstract}
resumo:
Este trabalho buscou analisar as principais características da força de trabalho em saúde no Brasil a partir do recorte do complexo econômico industrial da saúde (CEIS). Esta perspectiva de análise do setor saúde engloba tanto as instituições responsáveis pela oferta de serviços de saúde, quanto as indústrias produtoras de tecnologias médicas, corroborando a visão de que o setor saúde pode contribuir tanto para o bem-estar da população quanto para o desenvolvimento econômico, a partir da geração de renda, emprego e inovações tecnológicas. Estudos sobre essa temática mostram-se relevantes já que o Brasil possui, de forma estratégica, grande potencial de produção científica na área de saúde que, atualmente, é subaproveitado pelas indústrias médicas. Além disso, o país conta com um sistema público e universal de saúde com grande capacidade de absorção de mão-de-obra. Desta forma, o complexo da saúde configura-se como uma janela de oportunidade para o desenvolvimento do país, sendo necessária a compreensão das dificuldades estruturais e políticas enfrentadas para sua construção.

Tendo como foco, portanto, a força de trabalho do complexo da saúde, este estudo buscou estimar a dimensão desta força de trabalho e algumas particularidades de suas relações de trabalho. As informações foram retiradas da base de dados da PNAD-IBGE, para os anos de 2004, 2011, 2014 e 2015, respectivamente. A escolha desses anos em específico foi motivada pela tentativa de mensurar a dinâmica da força de trabalho em saúde no cenário de crescimento econômico, realização de investimentos e estabilidade que caracterizou a economia do país até 2015.

O estudo revelou a importância crescente do complexo da saúde para a geração de emprego no país nos últimos anos, mas com algumas particularidades. Destacam-se o peso do setor público na contratação destes trabalhadores, a concentração desta força de trabalho na região Sudeste e a baixa participação das indústrias médicas na empregabilidade destes profissionais, em comparação com 0 setor de serviços. Concluiu-se pela necessidade de elaboração de políticas que contemplem esta força de trabalho e fortaleçam a construção do CEIS, visto que este segmento econômico constitui-se como importante estratégia para o desenvolvimento dos sistemas de bem-estar e inovação no Brasil.
\end{abstract}

palavras-chave:

complexo econômico industrial da saúde; força de trabalho em saúde; Brasil

Código JEL: I18; J2; L52

Área Temática: 4.3 Sistemas de inovação - nacional, regional, setorial, tecnológico 


\section{Introdução}

Tem se tornado consenso a ideia de que o setor saúde figura, simultaneamente, em duas dimensões consideradas estratégicas: a sanitária e a econômica. De um lado, avanços nos sistemas de atenção à saúde impactam a qualidade de vida e o bem-estar de uma população. De outro, o setor saúde constituise como um foco de geração de emprego, investimento e inovações tecnológicas. Desta forma, o desenvolvimento de políticas de saúde bem articuladas com o sistema produtivo pode se constituir como um importante vetor de desenvolvimento econômico para as nações capitalistas contemporâneas (GADELHA, 2010).

Dada a importância econômica do setor saúde, e a necessidade de abordá-lo a partir de uma perspectiva mais ampla, para além das atividades e ocupações típicas dos serviços de saúde, este artigo busca apresentar dados sobre as características gerais e a evolução da força de trabalho presente no complexo econômico industrial da saúde (CEIS) no Brasil nas últimas duas décadas. Esta proposta de análise mostra-se relevante pela importância teórica e política que tem tomado a discussão sobre o CEIS no país, e pela influência que o trabalho exercido neste complexo tem para a oferta dos serviços de saúde e para as dinâmicas econômica e de inovação. Além disso, poucos esforços na literatura têm se dedicado a essa discussão, o que reforça a necessidade de realização de mais estudos sobre o assunto.

As próximas seções estão organizadas da seguinte maneira. O item 2 apresenta o conceito do complexo econômico industrial da saúde e enfatiza a importância deste arranjo para a geração de emprego, renda e inovação e para a promoção do desenvolvimento econômico do país. $\mathrm{O}$ item 3 descreve alguns estudos de destaque na literatura que propuseram uma mensuração da força de trabalho em saúde no Brasil a partir dos recortes do macrossetor saúde e do complexo da saúde, os quais se constituíram como referência para a elaboração deste estudo, e também a nova proposta metodológica de estimação desta força de trabalho, que combina ideias já trabalhadas por outros autores com sugestões/adaptações próprias. No item 4, são apresentados e analisados indicadores sobre a força de trabalho no CEIS referentes ao período de 2004 a 2015. O grupo de informações descreve: quem e quantos são os trabalhadores do CEIS; onde estão alocados (segmentos econômicos); como estão distribuídos (setores público e privado e regiões geográficas); e como estão configurados alguns aspectos das relações de trabalho (contribuição para previdência e posição na ocupação). Já a última seção apresenta as principais conclusões obtidas a partir do levantamento dos dados, as quais remetem à importância crescente do CEIS na empregabilidade de trabalhadores, com algumas especificidades importantes (grande participação do setor público na geração de empregos, e a concentração destes no segmento de serviços de saúde e em algumas regiões do país).

\section{O Complexo Econômico Industrial da Saúde}

A caracterização do setor saúde a partir de uma perspectiva sistêmica, como intersecção entre dois sistemas fundamentais, o de saúde e o de inovação, tem sido bastante explorada na literatura nas últimas décadas. Albuquerque e Cassiolato (2000) trabalham com o conceito de sistema de inovação do setor saúde, doravante SNI saúde, onde a articulação e as relações estabelecidas entre as indústrias da área da saúde (farmacêutica, biotecnológica e de equipamentos médico-hospitalares), as universidades, os institutos de pesquisa, os laboratórios, as instituições de assistência médica (hospitais, clínicas etc), os órgãos de regulação e de saúde pública, e os atores sociais (usuários e profissionais da saúde) constituiriam a origem e a dinâmica do progresso tecnológico na área da saúde.

Para os autores, cada um dos componentes do SNI saúde possui funções específicas e estratégicas. As universidades e os institutos de pesquisa provêm o fluxo e a troca de informações científicas e tecnológicas; as instituições responsáveis pela assistência médica, as outras instituições não mercantis e os profissionais de saúde influenciam a dinâmica da geração e da difusão de inovações; e os órgãos de saúde pública recebem as inovações geradas pelas indústrias do setor. A Figura 1 descreve este arranjo institucional e suas interações. 
Figura 1 - Fluxos de informações científicas e tecnológicas no sistema de inovação do setor saúde: o caso de países com sistemas maduros

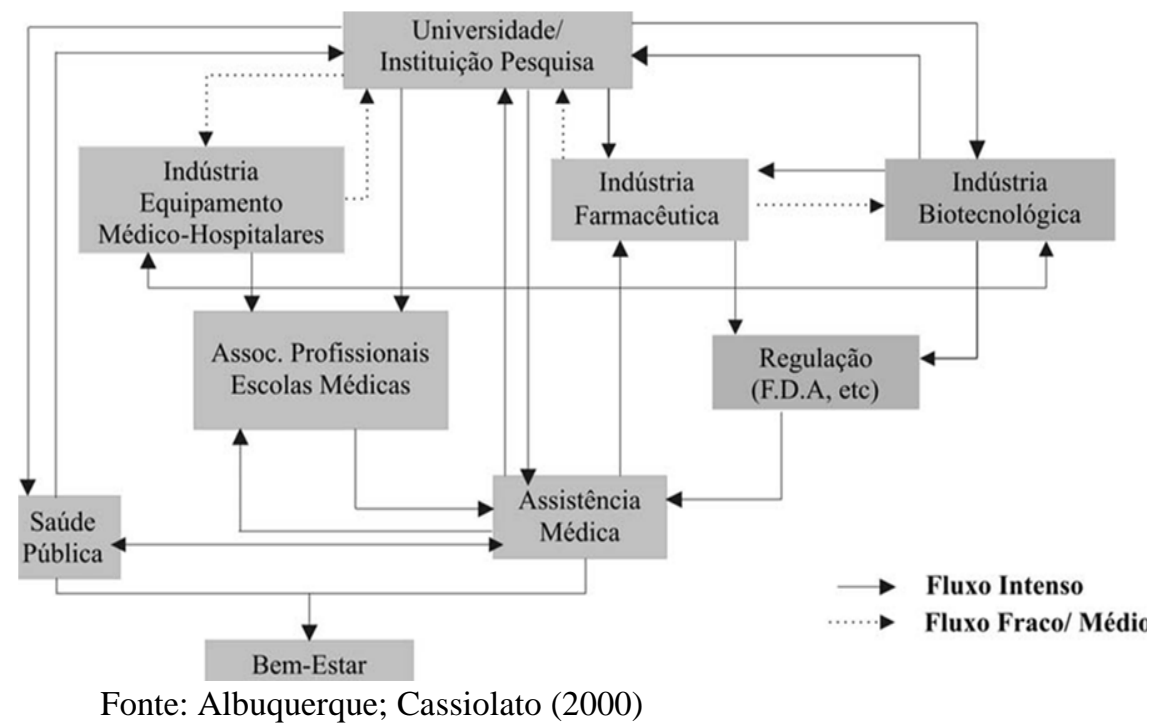

Outro grupo de pesquisadores brasileiros, a partir da junção do referencial teórico da Saúde Pública e da Economia Política, e da concepção de desenvolvimento a partir das dimensões econômica e social, propôs, no início dos anos 2000, o desenho do que doravante seria denominado como complexo econômico industrial da saúde (GADELHA; TEMPORÃO, 2018). Uma das referências principais deste conceito, Gadelha $(2003$; 2006) inaugurou a expressão "complexo industrial da saúde", que seria um recorte do sistema de inovação do setor saúde com o objetivo de atribuir ênfase à dinâmica produtiva do setor saúde. Neste complexo, as indústrias médicas estariam operando sob a lógica capitalista de produção, sendo responsáveis pela geração de emprego, renda, investimentos, inovações tecnológicas e, consequentemente, pela acumulação de capital. No entanto, os interesses destas indústrias não necessariamente estariam convergindo com as demandas do sistema de atenção à saúde, sugerindo a necessidade de uma atuação eficiente do Estado no sentido de combinar políticas industriais e de saúde e de subordinar as atividades das indústrias do setor aos interesses de saúde da população em geral.

A visão sistêmica e estrutural da relação entre o SUS e a base produtiva e de inovação em saúde consolida o conceito de complexo econômico industrial da saúde, onde a demanda social pelo acesso a bens e serviços e a estrutura industrial incumbida desta oferta estão fortemente interligadas. O CEIS, portanto, seria formado por três subsistemas: o de "base química e biotecnológica", o de "base mecânica, eletrônica e de materiais" e o de "serviços de saúde". A Figura 2 detalha as características dos três subsistemas e descreve o fluxo de relações entre eles (GADELHA et al. 2012).

Figura 2 - Caracterização geral do Complexo Econômico Industrial da Saúde

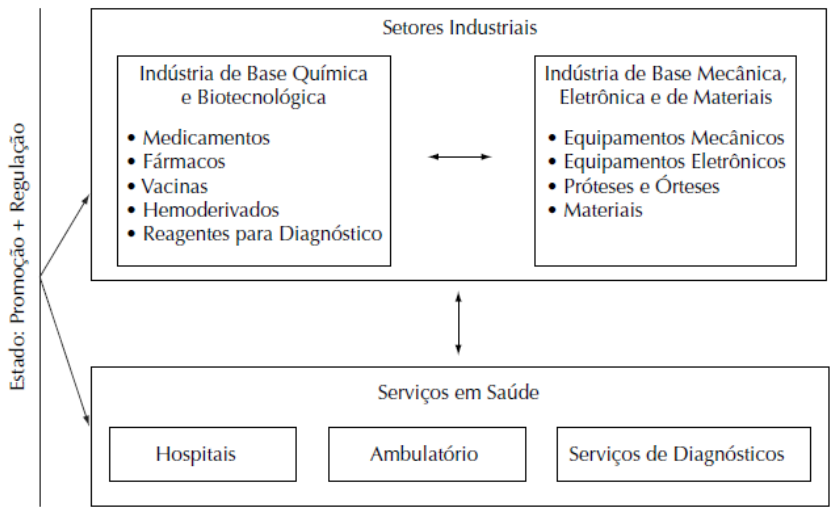

Fonte: Gadelha et al. (2012) 
Segundo Gadelha e Temporão (2018), quatro matrizes de pensamento responsáveis pela compreensão da dinâmica do sistema capitalista constituem a base teórica central do conceito do CEIS: a marxista, a schumpeteriana, a estruturalista (ênfase na visão de Celso Furtado) e a keynesiana.

As visões de Marx e Schumpeter de que o sistema capitalista encontra-se sob constantes modificações graças às inovações tecnológicas são incorporadas no CEIS, onde as inovações em saúde transformam permanentemente a dinâmica da oferta dos serviços de saúde no SUS. A tradição sistêmica dos neoshumpeterianos sobre a dinâmica de inovação também é captada pelo CEIS, que ao figurar como intersecção entre os sistemas de saúde e inovação, escapa da perspectiva de visão unívoca entre bens industriais como insumos, e serviços de saúde como resultado.

A perspectiva dialética de Marx se reflete na visão da saúde como um espaço contraditório, onde ao mesmo tempo em que circula o capital, e há geração de investimento, renda, emprego, conhecimento e inovação, gera-se também desigualdade e exclusão.

O caráter desigual e concentrado da dinâmica da inovação, que conforma a divisão internacional entre centro e periferia, e propicia a esta última a combinação de processos de modernização com marginalização, está presente na abordagem do CEIS, em uma clara alusão à visão estruturalista do desenvolvimento. A expansão do acesso aos serviços de saúde nas últimas décadas encontra barreiras estruturais, como a dependência de tecnologias estrangeiras. $\mathrm{O}$ déficit crescente da balança comercial do CEIS escancara a fragilidade técnica e científica do país na saúde e se constitui em um empecilho à concretização de políticas universais de saúde.

Por último, a importância da ação do Estado na dinâmica do CEIS reflete o paradigma keynesiano de defesa de realização de investimentos e intervenções por parte dos governos. No contexto do CEIS, o Estado deve elaborar e implementar políticas públicas que contribuam para o alinhamento das dinâmicas produtiva, de inovação e de bem-estar, contribuindo assim para a garantia do desenvolvimento econômico de longo prazo (GADELHA; TEMPORÃO, 2018).

A conceituação do CEIS permite verificar a importância do desenvolvimento de uma base produtiva e de um ambiente favorável às inovações para o atendimento das demandas de saúde da população brasileira. E a perspectiva sistêmica desse segmento se dá não só pela relação entre os setores industriais e de serviços, mas também pelo fato de que estes segmentos “(...) compartilham o mesmo arcabouço político institucional, ou seja, o ambiente regulatório, as diretrizes de política social, econômica, industrial e a estrutura político-institucional do sistema nacional de saúde" (GADELHA et al., 2012; p. 23).

Cada segmento possui um papel e uma importância específica no complexo. O setor de base "química e biotecnológica" disponibiliza produtos diretamente consumidos pela população, como medicamentos e vacinas, por isso sua importância na discussão sobre universalidade dos serviços de saúde. Além disso, é um setor dependente de tecnologias estratégicas, como a nanotecnologia, sinalizando janelas de oportunidade importantes para ganhos de competitividade. O país apresenta espaço para avançar na consolidação deste setor combinando expansão do mercado consumidor e internalização da produção e da inovação. Algumas oportunidades já estão sendo exploradas como a produção de genéricos e fitoterápicos.

Em relação ao subsistema de base "mecânica, eletrônica e de materiais", é possível afirmar que este

(...) exerce particular influência sobre o formato da prestação de serviços em saúde, dada a forte associação de seus produtos às práticas médicas. Ao articular tecnologias diversas, incorporadas nos procedimentos médicos relativos à prevenção, ao diagnóstico e ao tratamento de doenças, esse subsistema também ilustra a relação entre as lógicas econômica e social do desenvolvimento. Esse subsistema é bastante heterogêneo, abrangendo desde a produção de equipamentos com alta sofisticação tecnológica, como por exemplo o 'diagnóstico por imagens', até instrumentos cotidianos. Os segmentos mais complexos desse subsistema baseiam-se intensamente em tecnologias estratégicas, a exemplo da microeletrônica, mecânica de precisão, química fina e novos materiais (GADELHA et al., 2012; p. 25 e 26). 
Ressalta-se que ao longo da década de 2000 esse segmento ganhou dinamismo expressivo ao acompanhar a expansão da rede de assistência do SUS. As respectivas atividades industriais apresentaram aumento do faturamento, do número de empresas ativas no mercado, do volume de exportações e, também, dos empregos gerados (GADELHA et al., 2012).

O subsistema de serviços é o maior e mais importante segmento do CEIS. Abrange uma infinidade de serviços de diferentes complexidades: postos de saúde, ambulatórios, consultórios médicos, hospitais e centros de diagnóstico e terapia. Seu papel estratégico se dá não só pelo seu peso na geração de emprego e renda, mas também pela sua função de demandante e indutor das tecnologias produzidas, como equipamentos médico-hospitalares, materiais cirúrgicos, medicamentos e as Tecnologias de Informação. Papel de destaque é atribuído aos hospitais e aos centros de diagnóstico neste processo de geração e absorção de inovações. O setor de serviços também tem grande relevância no desenvolvimento de inovações nas práticas médicas, as quais muitas vezes dependem das atividades das indústrias do complexo. Por isso as interações entre prestadores de serviços e indústrias e entre profissionais da saúde e de Pesquisa e Desenvolvimento (P\&D) (GADELHA, 2012; GADELHA et al., 2012).

O contexto atual revela a necessidade de reestruturação do segmento de serviços de saúde, de modo a garantir o cumprimento dos preceitos do SUS. Este enfrenta tanto desafios conjunturais, como o aumento da expectativa de vida da população, a mudança do perfil epidemiológico das doenças, e o aumento dos custos da atenção à saúde, quanto problemas estruturais persistentes, como o subfinanciamento do sistema e o peso significativo do setor privado. Para além das necessidades do SUS, a imprescindibilidade da reorganização dos serviços de saúde coloca-se como uma agenda mundial, que busque garantir a combinação de expansão do acesso aos serviços de saúde com racionalização de custos (COSTA et al., 2012).

As tecnologias organizacionais e de novos produtos mostram-se fundamentais nesse processo. Desde que sejam superadas as contradições entre os interesses econômicos e sociais através de uma ação eficiente do Estado, "(...) a inovação apresenta-se como variável-chave para a reestruturação dos serviços de saúde" (COSTA et al., 2012; p. 78). A incorporação de novos equipamentos, medicamentos, procedimentos, e profissionais diferenciados, a conformação de redes integradas de saúde, o foco na atenção primária, a incorporação das tecnologias de informação e comunicação (TICs), a transformação do papel dos hospitais, voltados para cuidados intensivos, são exemplos de iniciativas que "(...) têm propiciado alterações da infraestrutura física instalada no País e acesso aos profissionais de saúde no território brasileiro, ainda que de modo incipiente no Brasil até o momento" (COSTA et al., 2012; p. 78).

A utilização eficiente de tecnologias médicas combinada à expansão da participação pública nos gastos com saúde, à atuação estratégica de instituições públicas como a Fiocruz, o Ministério da Saúde e de determinados hospitais universitários constituem-se como elementos essenciais para a dinâmica do segmento dos serviços de saúde. Para Gadelha (2012), o desenvolvimento do setor pode ser uma alavanca para o crescimento do PIB e para a geração de mais de dez milhões de empregos, com impacto positivo também sobre a qualidade do trabalho.

É importante ressaltar que algumas iniciativas importantes para direcionar a ação do Estado na perspectiva sistêmica de consolidação do CEIS foram desenvolvidas a partir de 2008 no Brasil. Em primeiro lugar, tem-se a incorporação do desenvolvimento do CEIS como parte das intenções do Programa Mais Saúde (2008-2011). Em seguida destaca-se a Política de Desenvolvimento Produtivo (PDP), que deu destaque ao complexo na agenda da política industrial brasileira. E, finalmente, foram desenvolvidas as Parcerias para o Desenvolvimento Produtivo, que utilizaram do poder de compra do Estado para tentar combinar o atendimento das demandas dos pacientes do SUS com o fortalecimento de cadeias produtivas nacionais.

Nota-se, portanto, que as principais ferramentas utilizadas nas últimas décadas com o objetivo de impactar positivamente o CEIS envolveram o uso da capacidade de compra do Estado, a implementação de políticas voltadas para a o financiamento e a promoção das indústrias do setor saúde, e a constituição de um arranjo de instituições de excelência (GADELHA; BRAGA, 2016).

Apesar das ações de destaque dos últimos anos, ainda há muito a se avançar na superação da visão fragmentada da implementação de políticas e na articulação de iniciativas sociais, econômicas e tecnológicas de forma sistêmica, de modo a combinar expansão dos serviços de saúde com capacitação 
tecnológica e industrial. A exclusão de grande parte da população ao acesso a bens e serviços de saúde, o persistente déficit da balança comercial de saúde brasileira descrito anteriormente, e o distanciamento da capacidade inovativa nacional da fronteira tecnológica internacional são evidências do quadro ainda frágil de construção do CEIS no país (GADELHA et al., 2012; GADELHA; BRAGA, 2016).

Conclui-se que a abordagem da saúde a partir da caracterização do CEIS, com o fortalecimento da relação virtuosa entre saúde e desenvolvimento econômico, mostra-se de extrema relevância, principalmente na conjuntura atual, de crise econômica, sanitária e desmonte do Estado social. Estimativas apontam que além de sua importância para a dinâmica de inovação e para a conformação do sistema de saúde brasileiro, o CEIS possui uma participação estratégica na economia brasileira. Ao final da primeira década de 2000, o complexo respondia por 5\% do total da produção do país e pela geração de mais de quatro milhões de empregos (10\% do emprego qualificado do país). Em 2015, o total de empregos gerados já girava em torno de seis milhões e quinhentos mil.

Cabe ao Estado, dessa forma, liderar e guiar o processo de consolidação da estrutura do CEIS no país, segundo a lógica descrita na Figura 3 (GADELHA, 2012; GADELHA; TEMPORÃO, 2018).

Figura 3 - Políticas para o desenvolvimento do CEIS - Síntese

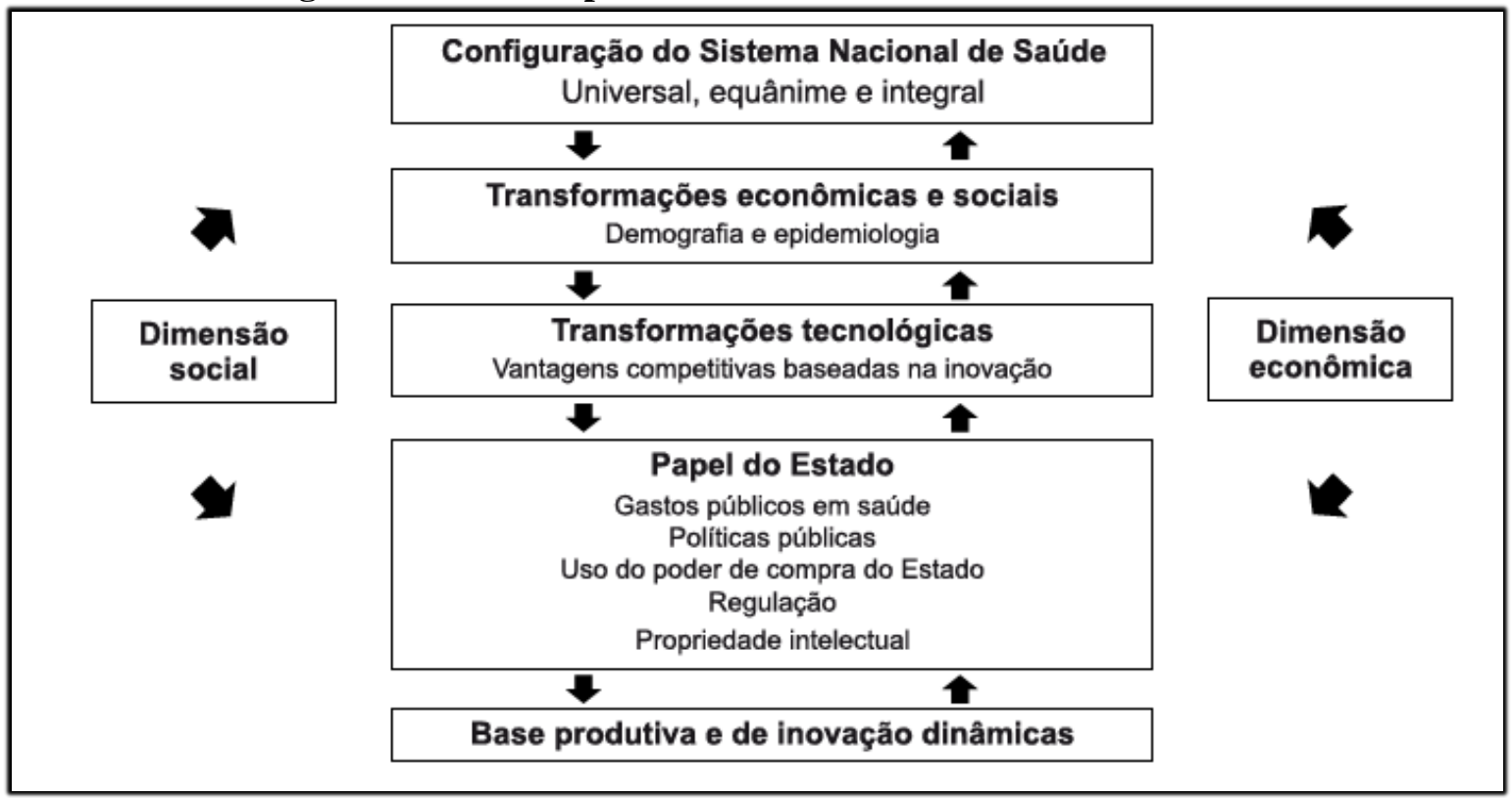

Fonte: Gadelha (2012)

A complexidade do arranjo das políticas que devem ser implementadas reflete as diversas facetas que caracterizam o setor saúde quando analisado sob o recorte do CEIS: é ao mesmo tempo um direito social, um bem econômico e um espaço de acumulação de capital; um sistema produtivo intensivo em mão-de-obra e de consumo de massa; e uma área estratégica para o desenvolvimento dos sistemas de bem-estar e inovação (GADELHA, 2012; COSTA et al., 2013). Esta visão vai muito além de uma perspectiva funcionalista da saúde, considerada apenas “(...) como 'capital humano', como elemento para o exercício da liberdade de escolha individual, ou como um 'insumo' para o desenvolvimento macroeconômico" (GADELHA; BRAGA, 2016; p. 10). Portanto, ao promover a consolidação de um sistema de saúde universal e equânime a partir de uma ótica ampla e sistêmica, o Estado também estará orientando e regulando o capital, bem como criando as bases para a configuração de um Estado de BemEstar Social.

\section{Mensuração da força de trabalho no complexo econômico industrial da saúde: aspectos metodológicos}


Apesar da importância da discussão, não há muitos estudos disponíveis na literatura que buscam mensurar a força de trabalho em saúde no Brasil a partir de uma perspectiva mais ampla, incluindo outras atividades econômicas além dos serviços de saúde. Trata-se de um esforço que tem sido tentado, nos últimos anos, por poucos grupos de pesquisadores. Os desafios passam pela definição precisa de quem são os trabalhadores da saúde e em quais setores econômicos estão distribuídos. E, também, pelas limitações das bases de dados.

Uma importante publicação sobre metodologia de análise de bases de dados referentes ao mercado de trabalho em saúde foi disponibilizada em 2013, pela Estação de Pesquisa de Sinais de Mercado, do Observatório de Recursos Humanos em Saúde, da Faculdade de Medicina da Universidade Federal de Minas Gerais, sob coordenação de Girardi e Maas. Os pesquisadores partiram de um recorte ampliado da força de trabalho em saúde, que seria formada pelos profissionais da saúde e pelos outros trabalhadores da saúde. Os primeiros seriam os indivíduos com formação e/ou capacitação específica na área de saúde, ocupados ou procurando trabalho não só nos serviços/atividades de saúde, como também em outros setores econômicos. Já os últimos não teriam formação e/ou capacitação específica na área de saúde, mas teriam que estar ocupados ou procurando trabalho necessariamente nos serviços/atividades de saúde.

As ocupações e os setores econômicos que compõem o que os autores denominaram de macrossetor saúde foram definidas com base na Classificação Brasileira de Ocupações (CBO) 2002, e na Classificação Nacional de Atividades Econômicas (CNAE) 2.0.

Para definir as ocupações diretamente relacionadas à prestação de serviços de saúde, foram analisadas a natureza do trabalho e as qualificações/habilidades exigidas para o exercício do mesmo, chegando-se assim a uma lista com diversas profissões de diferentes níveis de escolaridade. Já a delimitação das atividades econômicas baseou-se em estudo anterior de Nogueira e Girardi (1999), a partir do qual os pesquisadores chegaram à seguinte descrição:

I. Núcleo do setor - serviços produzidos em estabelecimentos especificamente voltados para a manutenção e recuperação da saúde, constituídas por atendimento hospitalar, atendimento de urgência e emergência, atenção ambulatorial, Serviços de Complementação Diagnóstica e Terapêutica (SADT) e atividades veterinárias; II. Atividades Complementares - seguridade social obrigatória, regulação de serviços de saúde, assistência social e psicossocial e atividades de ensino e Pesquisa e Desenvolvimento (P\&D) em saúde; III. Atividades industriais vinculadas aos serviços de saúde, constituídas por fabricação de preparações farmacêuticas, farmoquímicos, medicamentos; IV. Comercialização (atacadista e varejista) de produtos farmacêuticos, ópticos, ortopédicos, materiais de uso médico, cirúrgico, ortopédico e odontológico, e equipamentos odonto-médico-hospitalares; V. Atividades financeiras vinculadas à saúde, empresas de planos e seguros de saúde; VI. Atividades de saneamento constituídas pelas seguintes classes: captação, tratamento e distribuição de água, atividades relacionadas a esgoto e coleta, tratamento e disposição de resíduos. VII. Prestação de serviços de saúde realizada em estabelecimentos classificados em outro tipo de atividade econômica (GIRARDI; MAAS, 2013; p. 25).

Portanto, o total da força de trabalho em saúde para esses pesquisadores equivale à soma de dois grupos. O primeiro se refere ao estoque de profissionais de saúde, ou seja, indivíduos com formação/qualificação específica que podem atuar em qualquer setor econômico, uma vez que possuem habilitação para prestar atividades relacionadas à saúde. $\mathrm{O}$ segundo se refere ao grupo de outros trabalhadores da saúde, que não possuem educação específica na área de saúde, mas exercem atividades em estabelecimentos diretamente relacionados à oferta de serviços de saúde, ou seja, atuam no núcleo do setor.

Outras referências sobre estimativas da força de trabalho em saúde são os estudos de Dedecca (2008) e Dedecca e Trovão (2013). Estes autores procuraram delimitar a importância e o peso do setor saúde em relação ao mercado geral de trabalho e, para tanto, também trabalharam com uma perspectiva mais ampla desse setor, não se restringindo apenas aos empregos diretamente ligados aos serviços de 
saúde. O objetivo era escapar das visões tradicionais que abordavam o trabalho na saúde a partir da perspectiva de "recursos humanos" ou do recorte dos "profissionais presentes nas atividades-fim". Estas interpretações, apesar de importantes para orientar a formulação e implementação de políticas voltadas para o segmento de atenção à saúde, não seriam suficientes para explicar a dinâmica do trabalho no cenário atual, onde o avanço científico e tecnológico e as mudanças sociodemográficas abriram espaço para uma diversificação significativa dos serviços e também das atividades industriais. Sendo assim, o mercado de trabalho do setor saúde poderia ser pensado como "(...) um espaço ocupacional vinculado ao setor, que extrapola a dimensão das profissões ou dos recursos humanos específicos" (DEDECCA, 2008; p. 88).

Os autores dimensionaram a força de trabalho em saúde em seus estudos a partir das estatísticas domiciliares do IBGE (PNAD), devido à sua cobertura para a totalidade do mercado de trabalho. O recorte foi realizado por setores econômicos (CNAE Domiciliar) e por ocupações (CBO Domiciliar). Os primeiros foram agrupados em dois grandes segmentos de atividades, de acordo com a relação mais ou menos direta com os serviços de atenção à saúde: o de oferta direta de serviços de saúde, como hospitais, postos de saúde e clínicas, denominado de "núcleo"; e o de atividades ligadas à produção de fármacos, equipamentos, comércio de produtos médicos etc, denominado de "complementar". A descrição detalhada destes segmentos, formados pelos setores de "atividades fundamentais", "administração pública", "atividades complementares" e "atividades de apoio" é apresentada no Quadro 1.

\section{Quadro 1 - Setores da saúde a partir dos códigos da CNAE-Dom}

\begin{tabular}{|c|c|c|}
\hline Setores & $\begin{array}{c}\text { Códigos } \\
\text { CNAE-Dom }\end{array}$ & Denominações \\
\hline \multirow{3}{*}{$\begin{array}{l}\text { Atividades } \\
\text { Fundamentais }\end{array}$} & 85011 & Saúde pública \\
\hline & 85012 & Saúde particular \\
\hline & 85013 & Outras atividades de saúde \\
\hline \multirow{3}{*}{$\begin{array}{l}\text { Administração } \\
\text { Pública }\end{array}$} & 75011 & Administração do Estado e da política econômica e social - federal \\
\hline & 75012 & Administração do Estado e da política econômica e social - estadual \\
\hline & 75013 & Administração do Estado e da política econômica e social - municipal \\
\hline \multirow{3}{*}{$\begin{array}{l}\text { Atividades } \\
\text { Complementares }\end{array}$} & 75020 & Seguridade social \\
\hline & 80011 & Educação regular, supletiva e especial pública \\
\hline & 80012 & Educação regular, supletiva e especial privada \\
\hline \multirow{7}{*}{$\begin{array}{l}\text { Atividades de } \\
\text { Apoio }\end{array}$} & 24020 & Fabricação de produtos farmacêuticos \\
\hline & 33001 & Fabricação de aparelhos e equipamentos médico-hospitalares \\
\hline & 53063 & $\begin{array}{l}\text { Comércio de produtos farmacêuticos, médicos, ortopédicos, odontológicos e } \\
\text { de cosméticos e perfumaria }\end{array}$ \\
\hline & 66000 & Seguros e previdência privada \\
\hline & 67020 & Atividades auxiliares dos seguros e da previdência privada \\
\hline & 71030 & Aluguel de objetos pessoais e domésticos \\
\hline & 85030 & Serviços sociais \\
\hline Demais & & Demais Atividades Econômicas \\
\hline
\end{tabular}

Fonte: Dedecca (2008)

As ocupações foram definidas e divididas em "nucleares", "afins" e "demais/complementares". Esses três grupos também foram recortados de acordo com sua relação mais ou menos direta com os serviços de atenção à saúde. Mas, neste caso, os autores também levaram em consideração outros critérios. Nota-se que para as ocupações de saúde consideradas "nucleares", as quais inclusive constituem-se como objeto principal das pesquisas sobre recursos humanos, há um conjunto de restrições e regulamentações públicas específicas que definem as regras para o seu exercício, como as de médicos e enfermeiros. E essas ocupações são as principais responsáveis pela qualidade dos serviços de saúde prestados. As ocupações "afins" podem ou não ser influenciadas por alguma regulação específica do setor saúde, como é o caso dos biologistas e dos assistentes sociais. Em muitos casos, os profissionais deste grupo possuem uma formação mais geral, complementada por alguma habilitação específica, como é o caso dos profissionais que operam equipamentos. E as "demais ocupações" ou "ocupações 
complementares" estão sujeitas às regras gerais do mercado de trabalho, tais como motoristas e profissionais de alimentação e limpeza. A lista das ocupações é descrita no Quadro 2.

Quadro 2 - Ocupações do setor saúde a partir dos códigos da CBO-Dom

\begin{tabular}{|lcl|}
\hline Nível & $\begin{array}{c}\text { Código CBO-Dom } \\
(\text { Censo 2000) }\end{array}$ & Descrição \\
\hline & 2231 & Médicos \\
& 2232 & Cirurgiões-dentistas \\
& 2235 & Enfermeiros (nível superior) \\
& 3222 & Auxiliares de enfermagem (nível técnico) \\
Núcleo & 5151,5152 & Auxiliares de enfermagem prática (não-diplomados) e auxiliares de laboratório \\
& 2515 & Psicólogos \\
& 2236 & Terapeutas (fisioterapeutas e fonoaudiólogos) e trabalhos assemelhados de nível \\
& $3225,3224,3221$ & superior \\
\hline & 2211,2234 & Acupunturistas, técnicos em ortopedia, fisioterapia, protéticos e assemelhados \\
& 2237 & farmacologistas \\
Afins & 2516 & Nutricionistas e trabalhos assemelhados \\
& 3223 & Assistentes sociais e economistas domésticos \\
& 3241 & Ortoptistas e ópticos \\
\hline Demais & & Operadores de equipamentos médicos e odontológicos \\
\hline
\end{tabular}

Fonte: Dedecca (2008)

Ao cruzarem as ocupações com os setores econômicos, os autores chegaram a uma matriz correspondente ao que seria o complexo da saúde, conforme é descrito na Figura 4. Nota-se que as atividades e ocupações que estariam mais diretamente relacionadas com a oferta de serviços de saúde foram classificadas em um subgrupo denominado "núcleo". Já as demais estariam compondo o setor saúde expandido, sendo sua dinâmica dependente do "núcleo".

Figura 4 - Matriz-Síntese da composição do setor saúde

\begin{tabular}{|l|l|l|l|}
\hline \multirow{2}{*}{ Setores } & \multicolumn{3}{|c|}{ Ocupações } \\
\cline { 2 - 4 } & Núcleo & Afins & $\begin{array}{c}\text { Demais } \\
\text { Ocupações } \\
\text { (Corrigidas) }\end{array}$ \\
\hline Fundamentais & & & \\
\hline Administração Pública & & & \\
\hline Complementares & & & \\
\hline Apoio & & & \\
\hline Demais Setores & & & \\
\hline
\end{tabular}

Setor Saúde - Núcleo

Setor Saúde - Total

Fonte: Dedecca (2008)

Com base nessa proposição de composição do setor saúde e nos dados coletados da PNAD, os autores estimaram a população ocupada para todo o setor ou complexo da saúde e também para o núcleo. A Tabela 1 apresenta esses números em detalhe para o ano de 2009 e a Tabela 2 descreve a evolução da ocupação do complexo da saúde ao longo de três anos da primeira década de 2000. 
Tabela 1 - População ocupada no complexo da saúde - Brasil, 2009

\begin{tabular}{lrr|r|r}
\hline \multirow{2}{*}{ Segmentos } & \multicolumn{4}{c}{ Segmentos } \\
\cline { 2 - 5 } & Núcleo & Afins & Demais ocupações & \multicolumn{1}{c}{ Total } \\
\hline & \multicolumn{4}{c}{ População ocupada } \\
Fundamentais & 1.748 .813 & 32.976 & 1.094 .774 & 2.876 .563 \\
Adm. Pública & 486.564 & 92.027 & 414.221 & 992.812 \\
Complementares & 25.674 & 39.802 & 46.875 & 112.351 \\
Apoio & 153.899 & 184.049 & & 337.948 \\
Demais setores & 152.411 & & & 152.411 \\
Complexo Saúde (A) & 2.567 .361 & 348.854 & 1.555 .871 & 4.472 .086 \\
Complexo Saúde - Núcleo & & & & 2.425 .856 \\
População ocupada (B) & & & & 92.689 .253 \\
(A) / (B) & & & & 4,8 \\
\hline
\end{tabular}

Fonte: adaptado de Dedecca e Trovão (2013)

Tabela 2 - População ocupada do complexo da saúde - Brasil, 2003/2009

\begin{tabular}{lrrr}
\hline & \multicolumn{1}{c}{2003} & \multicolumn{1}{c}{2006} & \multicolumn{1}{c}{2009} \\
\hline Complexo da Saúde (A) & 3.526 .182 & 3.947 .293 & 4.472 .086 \\
Núcleo (B) & 1.815 .946 & 1.992 .442 & 2.425 .856 \\
População ocupada total (C) & 80.359 .109 & 88.725 .147 & 92.689 .253 \\
(B) / (A) & 51,5 & 50,5 & 54,2 \\
(A) / (C) & 4,4 & 4,4 & 4,8 \\
\hline
\end{tabular}

Fonte: Dedecca e Trovão (2013)

Por último, ressaltam-se o estudo coordenado por Gadelha (2012) e as estatísticas de emprego da Conta Satélite da Saúde do IBGE.

O trabalho realizado pelo Grupo de Inovação em Saúde, da Escola Nacional de Saúde Pública Sergio Arouca, da Fundação Oswaldo Cruz (GIS/Ensp/Fiocruz), e coordenado por Gadelha (2012), buscou descrever os aspectos relacionadas à dinâmica produtiva do setor saúde, ou seja, detalhar os elementos que compõem o CEIS no contexto da realidade econômica atual. A estimativa do total de ocupações gerada pelo CEIS não se constituiu como objetivo principal do estudo, mas foi utilizada como uma forma de ilustrar a importância do setor para a geração de emprego e renda. Essas informações foram retiradas do IBGE (Dados estatísticos, PNAD, e Conta Satélite da Saúde) e evidenciaram que, ao final da primeira década de 2000, o complexo da saúde respondia por $5 \%$ do total da produção do país e pela geração de mais de quatro milhões de empregos (10\% do emprego qualificado do país).

A Conta Satélite da Saúde constitui-se como uma extensão do Sistema de Contas Nacionais (SCN) e apresenta informações sobre produção, consumo final, comércio exterior, trabalho e renda, específicas para esse setor. Além da possibilidade de acompanhamento da evolução e da comparação com outros grupos de atividades, essas estatísticas reforçam o peso e a importância do setor saúde para a dinâmica econômica em geral. As atividades que compõem a Conta Satélite da Saúde têm como referência a CNAE 2.0 e os diversos indicadores relacionados a essas atividades são alimentados por diferentes bases de dados. De acordo com esta fonte de informações, o total de empregos gerados no setor girava em torno de seis milhões e quinhentos mil em 2015.

Todos os trabalhos descritos possuem o mérito de propor estimativas para a força de trabalho em saúde a partir de uma perspectiva ampliada, não restrita apenas aos serviços de saúde. E está é uma discussão fundamental, dada a janela de oportunidade existente no país para a consolidação do sistema de saúde enquanto um complexo, que engloba tanto o atendimento à população quanto a produção e comercialização de bens e serviços.

No entanto, entende-se que há algumas questões importantes que devem ser levantadas em relação a esses trabalhos. A proposta de Girardi e Maas (2013) para a classificação das ocupações e atividades econômicas do macrossetor saúde a partir da CBO 2002 e da CNAE 2.0, respectivamente, se adequa bem ao uso de bases de dados como a da Relação Anual de Informações Sociais (RAIS), mas nem tanto ao de estatísticas domiciliares como a da PNAD. E como a RAIS só engloba as atividades 
formais da economia, o universo estimado da força de trabalho através dessa base seria restrito. Além disso, questiona-se algumas profissões e atividades de saúde definidas por esses autores, como "recepcionistas de consultório médico ou dentário" e "atividades de saneamento", respectivamente.

Dedecca (2008) e Dedecca e Trovão (2013) propõem a utilização das classificações domiciliares da CBO e da CNAE, o que seria uma vantagem para a utilização de estatísticas mais amplas como as da PNAD, que permitem captar inclusive os trabalhadores autônomos. Mas, é importante ressaltar que a lista proposta de profissões de saúde por esses autores é um pouco restrita. Ocupações importantes, como os agentes comunitários de saúde, não constam na relação dos autores.

Já as estatísticas de Gadelha (2012) e da Conta Satélite de Saúde, apesar do detalhamento das atividades econômicas de saúde, que possibilitam estimação da participação do setor saúde na economia e realização de comparações ao longo do tempo, podem incorrer em algumas superestimações para o universo da força de trabalho em saúde. Como não há um filtro do cálculo da força de trabalho pelas ocupações, algumas classificações de atividades como a de comércio, acabam abrangendo um universo muito amplo de ocupações, não necessariamente relacionadas à saúde.

Levando-se em consideração essas questões, propõe-se, neste trabalho, um recorte metodológico para a estimativa da força de trabalho em saúde que combina e refina estas metodologias já existentes. É importante ressaltar que a complexidade do tema e da manipulação das bases de dados disponíveis estabelece significativas limitações para o levantamento dessas informações, que só podem ser superadas através de pesquisas de campo.

O ponto de partida principal da proposta deste artigo é o de que a força de trabalho em saúde deve ser estimada a partir da perspectiva do CEIS. Trata-se de uma estratégia relevante, já que as atividades deste segmento possuem capacidade significativa de geração de emprego e renda. A atuação dos trabalhadores do CEIS possui impacto tanto sobre a oferta de serviços de saúde, quanto sobre a dinâmica inovativa das indústrias do setor, duas áreas essenciais para a promoção do desenvolvimento do país.

A base de dados escolhida para levantar as informações foi a PNAD, já que assim seria possível abordar todo o universo de trabalhadores, sem restrição apenas aos formais ou aos que atuam somente em instituições de saúde. Os anos escolhidos para levantar as informações foram 2004, 2011, 2014 e 2015, de forma a captar o auge da expansão econômica e o início da crise, que perdura até os dias atuais.

As referências das atividades econômicas foram as listadas por Gadelha (2012) como segmentos do CEIS, as descritas na Conta Satélite da Saúde, e também os setores econômicos trabalhados na literatura como componentes do macrossetor ou complexo da saúde. Diante da necessidade de cruzar as informações com a base da PNAD, foi proposta neste trabalho uma relação de atividades econômicas pertencentes ao CEIS com correspondência com a CNAE - Dom. A descrição das atividades econômicas elencadas com seus respectivos códigos encontra-se no Quadro 3.

\section{Quadro 3 - Atividades econômicas do CEIS}

\begin{tabular}{|lll|}
\hline Agrupamentos & CNAE & Atividades \\
\hline \multirow{4}{*}{ Serviços de } & 85011 & Saúde pública \\
saúde & 85012 & Saúde particular \\
& 85013 & Outras atividades de saúde \\
\hline Indústrias & 85020 & Serviços veterinários \\
médicas & 85030 & Serviços sociais \\
\hline & 34020 & Fabricação de produtos farmacêuticos \\
& 53001 & Fabricação de aparelhos e equipamentos médico-hospitalares \\
\hline & 73063 & Comércio de produtos farmacêuticos, médicos, ortopédicos, odontógicos, \\
Outros & 66000 & cosméticos e de perfumaria \\
serviços & 67020 & Atividades auxiliares dos seguros e da previdência privada \\
& 73000 & Pesquisa e desenvolvimento \\
& 75011 & Administração do Estado e da política econômica e social - Federal \\
& 75012 & Administração do Estado e da política econômica e social - Estadual \\
& 75013 & Administração do Estado e da política econômica e social - Municipal
\end{tabular}


Quadro 3 - Atividades econômicas do CEIS "continuação"

\begin{tabular}{|lll|}
\hline Agrupamentos & CNAE & Atividades \\
\hline Outros & 80011 & Educação regular, supletiva e especial pública \\
serviços & 80012 & Educação regular, supletiva e especial particular \\
\hline
\end{tabular}

Fonte: IBGE - CNAE. Elaboração própria (2019)

A manutenção dos 'serviços veterinários' e dos 'serviços sociais' como parte dos "serviços de saúde", que poderia ser questionada com o argumento de que tais setores impactam pouco ou só indiretamente a saúde humana, se justifica pelo fato de o Ministério da Saúde reconhecer a Medicina Veterinária e o Serviço Social como profissões típicas da área da saúde, conforme será mencionado mais adiante.

Nota-se que além da inclusão dos serviços de oferta direta de saúde à população e das atividades industriais típicas da área médica, também se definiu como parte do CEIS um grupo complementar de serviços, essenciais para a dinâmica de todo o complexo. As mercadorias produzidas no setor industrial dependem, em grande medida, das 'atividades de P\&D' e, quando disponíveis no mercado, são comercializadas para os setores público e privado de saúde. As 'atividades de seguro e previdência privada' representam a participação crescente da saúde suplementar, ou seja, é o espaço de atuação do sistema financeiro. Trata-se de um fenômeno irreversível que, bem ou mal, possui impacto direto sobre a oferta de serviços de saúde.

Os segmentos de 'administração pública' e 'seguridade social' englobam instituições de saúde que não possuem personalidade jurídica própria e estão diretamente ligadas a órgãos da Administração direta. Especificamente na administração pública também está boa parte dos serviços de atenção básica, vinculados às secretarias de saúde ou ao Ministério da Saúde.

As 'atividades de educação', principalmente as universidades com seus departamentos de saúde, também podem abrigar instituições que prestam serviços de saúde sem personalidade jurídica própria (ambulatórios e centros de saúde pertencentes às universidades). Além disso, como a pesquisa da PNAD é declaratória, é possível captar no segmento de 'educação' indivíduos que se declaram profissionais da saúde, mas com ocupação principal de professores que também atendem nos hospitais universitários. A simples definição dos setores econômicos que fazem parte do CEIS não garante uma correta estimativa do total de trabalhadores de saúde existentes.

Nos segmentos das "indústrias médicas" e "outros serviços", há trabalhadores com diferentes formações e funções, muitos sem ligação alguma com atividades de saúde. Com base nesta reflexão, foi proposto um filtro do CEIS a partir das profissões de saúde.

Definiu-se uma lista com 28 códigos ocupacionais correspondentes à CBO - Dom que podem ser considerados da saúde. A construção desta lista baseou-se nos levantamentos realizados pelos trabalhos mencionados anteriormente, mas com algumas adaptações, pois algumas profissões foram excluídas, outras acrescentadas. $\mathrm{O}$ critério foi a percepção de necessidade de formação/capacitação específicas para o exercício de atividades de saúde e a lista das profissões de saúde definida pelo Ministério da Saúde (Resolução nº 287, de 8/10/1998, do Conselho Nacional de Saúde).

O Quadro 4 descreve as profissões de saúde com os respectivos códigos CBO. Nota-se que os profissionais em questão são tanto de nível superior quanto de nível técnico.

Quadro 4 - Profissões de saúde

\begin{tabular}{|ll|}
\hline CBO & Profissão \\
Dom & Nível superior \\
\hline 2211 & Biólogos, biomédicos e afins \\
2231 & Médicos \\
2232 & Cirurgiões-dentistas \\
2233 & Veterinários \\
2234 & Farmacêuticos \\
2235 & Enfermeiros de nível superior e afins \\
2236 & Fisioterapeutas, fonoaudiólogos, terapeuta ocupacional e afins \\
2237 & Nutricionistas
\end{tabular}




\begin{tabular}{|c|c|}
\hline $\begin{array}{l}\text { CBO } \\
\text { Dom }\end{array}$ & Quadro 4 - Profissões de saúde "continuação" \\
\hline & Nível superior \\
\hline 2391 & Profissionais da Educação Física \\
\hline 2515 & Psicólogos e psicanalistas \\
\hline 2516 & Assistentes sociais e economistas domésticos \\
\hline & Nível técnico \\
\hline 3221 & Técnicos em terapias alternativas e estéticas \\
\hline 3222 & Técnicos, atendentes e auxiliares de enfermagem \\
\hline 3223 & Técnicos em óptica e optometria \\
\hline 3224 & Técnicos e protéticos em saúde bucal \\
\hline 3225 & Técnicos em ortopedia \\
\hline 3231 & Técnicos em veterinária e zootecnia \\
\hline 3241 & Técnicos em equipamentos médicos e odontológicos \\
\hline 3242 & Técnicos e auxiliares técnicos em patologia clínica \\
\hline 3251 & Técnicos em manipulação farmacêutica \\
\hline 3253 & Técnicos de apoio à biotecnologia \\
\hline 3516 & Técnicos em segurança no trabalho \\
\hline 3522 & Agentes da saúde e do meio ambiente \\
\hline 5151 & Agentes Comunitários de Saúde e afins \\
\hline 5152 & Auxiliares de laboratório da saúde \\
\hline 5162 & Cuidadores \\
\hline 8103 & Mestre de Produção Farmacêutica \\
\hline 9153 & Reparador de equipamentos e instrumentos médico-hospitalares - excl. técnicos \\
\hline
\end{tabular}

A partir da listagem destas profissões, a força de trabalho em saúde foi estimada da seguinte maneira. No setor "serviços de saúde" todos os trabalhadores entraram para a estatística, independente de serem, ou não, profissionais de saúde. Portanto, neste grupo, há os profissionais de saúde e os outros trabalhadores da saúde. Esta proposta segue a ideia geral da literatura de que quem exerce atividades diretamente relacionadas à oferta de serviços de saúde pode ser considerado trabalhador da saúde, independente de sua formação. Por outro lado, nos segmentos de "indústrias médicas" e "outros serviços de saúde", foram contabilizados apenas os profissionais de saúde. A restrição a esses profissionais constituiu um filtro para retirar os trabalhadores não envolvidos em atividades de saúde nestes segmentos. No final, todos os profissionais e trabalhadores de saúde contabilizados no recorte do CEIS foram somados, de forma a se estimar o total da força de trabalho.

Antes de apresentar em detalhes os resultados encontrados, é necessário enfatizar uma especificidade desta proposta de recorte de dados. As metodologias anteriores (GIRARDI; MAAS, 2013; DEDECCA, 2008; DEDECCA E TROVÃO, 2013) propõem que as atividades econômicas não relacionadas com o setor saúde, mas que empregam profissionais de saúde, sejam consideradas como parte do macrossetor ou do complexo. Neste artigo, a proposta de definição do complexo da saúde está limitada às atividades que compõem o CEIS. Portanto, através deste recorte, não é possível identificar os profissionais de saúde que atuam em outros setores econômicos não presentes no CEIS. A metodologia proposta também não capta os outros trabalhadores da saúde que estão nas instituições que ofertam serviços de saúde classificadas como atividades da 'administração pública', 'seguridade social' ou 'educação'.

Portanto, por um lado, o recorte proposto pode significar perda de contabilização e subestimação da contagem de trabalhadores da força de trabalho em saúde. Mas, por outro, diante das limitações das bases de dados e das reflexões realizadas sobre as outras metodologias, entende-se que o refino proposto é necessário e adequado para estimar, de forma mais próxima à realidade, indicadores da força de trabalho em saúde presente no complexo econômico industrial da saúde. 


\section{Alguns indicadores da força de trabalho em saúde presente no CEIS}

As Tabelas 3 a e $3 b^{1}$ permitem uma visão geral da dimensão da força de trabalho em saúde nas atividades econômicas que fazem parte do CEIS.

Tabela 3a - Distribuição da força de trabalho em saúde segundo os agrupamentos das atividades econômicas do CEIS. Brasil, 2004/2011/2014/2015

\begin{tabular}{|c|c|c|c|c|c|c|c|c|}
\hline \multirow{2}{*}{$\begin{array}{c}\text { Agrupamentos das } \\
\text { atividades } \\
\text { econômicas } \\
\text { (CEIS) }\end{array}$} & \multicolumn{2}{|l|}{2004} & \multicolumn{2}{|l|}{2011} & \multicolumn{2}{|l|}{2014} & \multicolumn{2}{|c|}{2015} \\
\hline & Total & $\%$ & Total & $\%$ & Total & $\%$ & Total & $\%$ \\
\hline Serviços de saúde & 2.851 .354 & 3,3 & 3.599 .716 & 3,8 & 4.306 .120 & 4,3 & 4.562 .467 & 4,8 \\
\hline Indústria & 54.498 & 0,1 & 48.716 & 0,1 & 42.436 & 0,0 & 45.827 & 0,0 \\
\hline Outros serviços & 587.343 & 0,7 & 719.171 & 0,8 & 750.843 & 0,8 & 699.592 & 0,7 \\
\hline Total CEIS & 3.493 .195 & 4,1 & 4.367 .603 & 4,7 & 5.099 .399 & 5,1 & 5.307 .886 & 5,5 \\
\hline $\begin{array}{l}\text { Total da população } \\
\text { ocupada }\end{array}$ & 85.245 .933 & 100,0 & 94.763 .220 & 100,0 & 99.447 .612 & 100,0 & 95.380 .483 & 100,0 \\
\hline
\end{tabular}

Fonte: IBGE - PNAD. Elaboração própria (2019)

Tabela 3b - Distribuição da força de trabalho em saúde segundo as atividades econômicas do CEIS. Brasil, 2004/2011/2014/2015

\begin{tabular}{|c|c|c|c|c|c|}
\hline \multirow{6}{*}{$\begin{array}{l}\text { Serviços } \\
\text { de saúde }\end{array}$} & Atividades & 2004 & 2011 & 2014 & 2015 \\
\hline & Saúde pública & 934.686 & 1.491 .136 & 1.694 .725 & 1.809 .527 \\
\hline & Saúde particular & 1.439 .082 & 1.738 .526 & 2.138 .808 & 2.224 .953 \\
\hline & $\begin{array}{l}\text { Serviços Sociais e Outras atividades de } \\
\text { saúde }\end{array}$ & 429.255 & 324.542 & 391.709 & 452.292 \\
\hline & Serviços veterinários & 48.331 & 45.512 & 80.878 & 75.695 \\
\hline & Total & 2.851 .354 & 3.599 .716 & 4.306 .120 & 4.562 .467 \\
\hline \multirow{3}{*}{ Indústria } & Fabricação de produtos farmacêuticos & 9.982 & 14.461 & 15.095 & 18.731 \\
\hline & $\begin{array}{l}\text { Fabricação de aparelhos e equipamentos } \\
\text { médico-hospitalares }\end{array}$ & 44.516 & 34.255 & 27.341 & 27.096 \\
\hline & Total & 54.498 & 48.716 & 42.436 & 45.827 \\
\hline \multirow{5}{*}{$\begin{array}{l}\text { Outros } \\
\text { Serviços }\end{array}$} & $\begin{array}{l}\text { Comércio de produtos farmacêuticos, } \\
\text { médicos, ortopédicos, odontológicos, } \\
\text { cosméticos e de perfumaria }\end{array}$ & 31.327 & 80.386 & 58.631 & 66.438 \\
\hline & Seguros e previdência privada & 8.216 & 4.880 & 2.676 & 4.766 \\
\hline & $\begin{array}{l}\text { Administração do Estado e da política } \\
\text { econômica e social e Seguridade Social }\end{array}$ & 445.754 & 461.616 & 447.728 & 411.767 \\
\hline & $\begin{array}{l}\text { Educação regular, supletiva e especial e } \\
\text { Pesquisa e desenvolvimento }\end{array}$ & 102.046 & 172.289 & 241.808 & 216.621 \\
\hline & Total & 587.343 & 719.171 & 750.843 & 699.592 \\
\hline \multicolumn{2}{|c|}{ Total CEIS } & 3.493 .195 & 4.367 .603 & 5.099 .399 & 5.307 .886 \\
\hline \multicolumn{2}{|c|}{ Total da população ocupada } & 85.245 .933 & 94.763 .220 & 99.447 .612 & 95.380 .483 \\
\hline
\end{tabular}

\footnotetext{
${ }^{1}$ Algumas atividades da Tabela 3 b estão apresentadas de forma agregada, visando garantir a representatividade dos dados levantados. Pelo fato das informações da PNAD serem de caráter amostral, recortes muito específicos para os dados podem implicar em problemas de representatividade.
} 
Destaca-se, em primeiro lugar, o peso da força de trabalho em saúde em relação ao total da população ocupada. O percentual de ocupados da saúde subiu de 4,1\% em 2004 para 5,5\% em 2015, reforçando a tendência do complexo de ser intensivo em mão-de-obra, mesmo em um cenário de incorporação crescente de inovações tecnológicas.

No período de expansão econômica, compreendido entre 2004 e 2011, enquanto a taxa de crescimento média anual da população total ocupada foi de $1,5 \%$ a.a., a força de trabalho em saúde cresceu 3,2\% a.a. No intervalo de 2011 a 2014, momento em que a economia começou a dar sinais de arrefecimento, o mercado de trabalho em geral manteve o ritmo de crescimento anual do período anterior ( $1,6 \%$ a.a.), enquanto o número de trabalhadores da saúde aumentou em 5,3\% a.a.. E, de 2014 para 2015 , momento em que a crise se instalou no país, o mercado geral de trabalho encolheu em $4,1 \%$, mas as atividades econômicas do CEIS apresentaram crescimento do número de empregos gerados na mesma amplitude da queda geral: $4,1 \%$.

Os dados corroboram o dinamismo do complexo da saúde para a geração de emprego e sua contribuição para o comportamento do mercado de trabalho como um todo. Em 2015, o desempenho positivo do setor ajudou a compensar um pouco a queda geral de postos de trabalho.

Nota-se que a grande maioria dos trabalhadores da saúde encontra-se no segmento de "serviços de saúde", que em 2015 possuía 4,8\% do total da população ocupada do país. Este foi o único grupo em que o número de ocupados cresceu em todos os quatro anos do período analisado, sendo que o crescimento mais significativo foi verificado entre 2011 e 2014, equivalente a $6,15 \%$ a.a.

Neste grupo, as atividades de 'saúde particular' são as que concentram o maior número de trabalhadores, seguidas pelas de 'saúde pública'. Entre 2004 e 2011 o total de trabalhadores da 'saúde pública' apresentou maior aumento, com crescimento médio anual de $6,9 \%$ a.a.. No mesmo período, o crescimento do total de trabalhadores da 'saúde particular' foi de 2,74\% a.a.. Por outro lado, o número de trabalhadores da 'saúde particular' cresceu 7,15\% a.a. entre 2011 e 2014, média maior que a verificada para a 'saúde pública' no mesmo período, equivalente a 4,36\%. Já de 2014 para 2015, o total de trabalhadores da 'saúde pública' cresceu $6,8 \%$, e o da 'saúde particular', 4,02\%.

O segmento "outros serviços" aparece em segundo lugar no número de empregos em saúde gerados, tendo apresentado aumento da população ocupada nos anos de 2011, em relação a 2004, e 2014, em relação a 2011. Neste grupo, nota-se o número significativo de profissionais que atuam na 'administração pública', cujo total aumentou em 3,5\% entre 2004 e 2011. Este fato provavelmente estaria refletindo a ação dos programas de saúde comunitários do período, cuja gestão é de responsabilidade direta dos entes federados, principalmente das prefeituras. Já a queda do número de profissionais de saúde nesta atividade verificada a partir de 2011 poderia ser explicada, em parte, pelos efeitos da desaceleração econômica sobre o orçamento das atividades/instituições de saúde vinculadas diretamente à Administração Pública, particularmente nos níveis federal e estadual.

O crescimento de $137 \%$ dos profissionais de saúde atuando nas atividades de 'educação e P\&D' entre 2004 e 2014 evidencia a importância do envolvimento destes profissionais com as práticas do ensino e das pesquisas básica e aplicada em saúde.

O comportamento dos profissionais de saúde envolvidos com as atividades de 'comércio de produtos' do setor evidencia maior dinamismo entre 2004 e 2011 , período em que o número desses profissionais aumentou em $156 \%$. Já a presença de profissionais de saúde envolvidos com 'atividades de gestão e avaliação de riscos de seguros de saúde' é modesta, apresentando tendência de queda entre 2004 e 2014.

No que diz respeito ao segmento da "indústria", nota-se que esta apresenta uma participação ainda muito residual na empregabilidade de profissionais da saúde. Essa baixa participação das indústrias da saúde na geração de empregos para o setor reflete a ausência de políticas voltadas para a internalização da produção de tecnologias médicas. A atividade de 'fabricação de produtos farmacêuticos' chegou a apresentar um comportamento positivo no período analisado, praticamente dobrando o número de profissionais empregados entre 2004 e 2015. Este resultado pode estar retratando a iniciativa de Política Industrial, Tecnológica e de Comércio Exterior (PITCE), implementada pelo governo Lula a partir de 2004, cujo um dos focos foi a promoção do desenvolvimento de setores estratégicos, como o de fármacos e medicamentos. O já mencionado crescimento de $137 \%$ do número de profissionais de saúde em atividades de 'educação e P\&D' entre 2004 e 2014 vai ao encontro dos 
objetivos do governo de alavancar a indústria farmacêutica, que depende diretamente das atividades de P\&D para sobreviver no mercado.

As iniciativas mencionadas foram importantes, mas ainda sim tímidas e de baixo impacto. Sua fragilidade estrutural é desvendada nos momentos de crise. Entre 2014 e 2015 o número de profissionais de saúde envolvidos em atividades de 'educação e P\&D' diminuiu 10,4\%.

Ao contrário do bom comportamento da indústria farmacêutica, a atividade de 'fabricação de aparelhos e equipamentos médico-hospitalares' apresentou queda de 39\% no número de empregos gerados entre 2004 e 2015. Isso indica dificuldades de atribuir dinamismo à produção interna dessas tecnológicas médicas, o que reforça o déficit da balança comercial correspondente a esse segmento, conforme já mencionado.

Nota-se, portanto, que o setor industrial ainda não teve explorado todo o seu potencial para a geração de emprego e, consequentemente, de renda, no CEIS brasileiro. A vitalidade do complexo ainda é praticamente garantida pelos "serviços de saúde".

Nota-se que os dados da Tabela 3.b não permitem conclusões gerais a respeito da distribuição da força de trabalho em saúde por natureza jurídica, uma vez que atividades públicas e privadas de oferta de serviços de saúde estão espalhadas nos segmentos de "serviços de saúde" e "outros serviços". Desta forma, construiu-se a Tabela 4, que cruza os três segmentos do complexo com os setores público e privado, de forma agregada.

Tabela 4 - Distribuição percentual da força de trabalho em saúde segundo a natureza jurídica 2004/2011/2014/2015

\begin{tabular}{|c|c|c|c|c|c|c|c|c|c|c|c|c|}
\hline \multirow{2}{*}{$\begin{array}{l}\text { Agrupamentos das atividades } \\
\text { econômicas (CEIS) }\end{array}$} & \multicolumn{3}{|c|}{2004} & \multicolumn{3}{|c|}{2011} & \multicolumn{3}{|c|}{2014} & \multicolumn{3}{|c|}{2015} \\
\hline & Privado & Público & Total & Privado & Público & Total & Privado & Público & Total & Privado & Público & Total \\
\hline Serviços de saúde & 56,4 & 43,6 & 100,0 & 49,2 & 50,8 & 100,0 & 51,0 & 49,0 & 100,0 & 50,3 & 49,7 & 100,0 \\
\hline Indústria & 100,0 & 0,0 & 100,0 & 90,3 & 9,7 & 100,0 & 100,0 & 0,0 & 100,0 & 100,0 & 0,0 & 100,0 \\
\hline Outros serviços & 13,0 & 87,0 & 100,0 & 18,6 & 81,4 & 100,0 & 17,9 & 82,1 & 100,0 & 20,0 & 80,0 & 100,0 \\
\hline Total CEIS & 48,4 & 51,6 & 100,0 & 44,0 & 56,0 & 100,0 & 45,8 & 54,2 & 100,0 & 46,1 & 53,9 & 100,0 \\
\hline
\end{tabular}

De acordo com os dados da Tabela 4, os empregos no setor público superam os do setor privado em todos os anos analisados. O maior percentual ocorre no ano de 2011, onde os empregados públicos chegam a representar $56 \%$ da força de trabalho em saúde. Isto estaria refletindo o crescimento médio anual dos postos de trabalho do setor público, de 5,08\% a.a., acima do valor verificado para o setor privado, equivalente a 2,46\% a.a., entre 2004 e 2011. No período seguinte, entre 2011 e 2014 , as vagas no setor privado aumentaram em 6,31\% a.a., enquanto as do setor público em 3,76\% a.a.. Por isso, a participação do setor público na empregabilidade da força de trabalho em saúde cai para $54,2 \%$ em 2014 , enquanto a do setor privado aumenta de $44 \%$ para $45,8 \%$.

E de 2014 para 2015, o setor privado também superou o setor público na geração de novas vagas: o primeiro com aumento de 4,8\%, em comparação com os 3,22\% do segundo. Por isso o percentual de empregados no setor privado aumenta para $46,1 \%$, enquanto o do setor público diminui para 53,9\%.

É possível concluir a partir disso que mesmo ainda sendo o maior empregador da força de trabalho em saúde, o setor público tem perdido dinamismo na geração de postos de trabalho, enquanto o setor privado, ao contrário, tem ganhado cada vez mais expressão. Esta situação ocorre especialmente nos momentos de crise, onde os gargalos do sistema público de saúde se intensificam e abre-se espaço para atuação do setor privado na oferta de serviços de saúde.

Destaca-se também a concentração de profissionais de saúde nas indústrias farmacêutica e de equipamentos médicos do setor privado, com uma participação um pouco mais expressiva do setor público apenas em 2011, provavelmente como reflexo das iniciativas da PITCE².

\footnotetext{
${ }^{2}$ É importante explicar que o percentual equivalente a zero de profissionais nas indústrias da saúde no setor público para os anos de 2004, 2014 e 2015 equivale a valores amostrais absolutos muito pequenos em relação ao total.
} 
No que diz respeito à distribuição geográfica dos trabalhadores do CEIS, é possível afirmar que há uma concentração dos mesmos na região Sudeste. Em todo o período analisado, o Sudeste reuniu em torno de 50\% dos trabalhadores do complexo, conforme mostra a Tabela 5, enquanto sua população gira em torno de $42 \%$ da do total do país. Nas regiões Norte e Nordeste ocorreu o inverso, sendo a proporção populacional maior do que o percentual de trabalhadores do complexo. Em 2004, o Norte detinha 5,5\% dos trabalhadores, enquanto o Nordeste $19,7 \%$, e suas populações correspondiam a 7,9\% e $27,8 \%$ da de todo o país, respectivamente. Em 2015, a situação permanece praticamente a mesma. O Norte possuía $6,1 \%$ dos trabalhadores e $9 \%$ da população, enquanto o Nordeste registrava $21 \%$ do total da força de trabalho do complexo da saúde e $28 \%$ da população total. Apenas nas regiões Sul e Centro-oeste, a divisão dos trabalhadores da saúde se mostrou compatível com seus respectivos volumes populacionais.

Tabela 5 - Distribuição percentual da força de trabalho em saúde por região brasileira. 2004/2011/2014/2015

\begin{tabular}{|c|c|c|c|c|c|c|c|c|c|c|c|c|}
\hline \multirow{2}{*}{$\begin{array}{c}\text { Agrupamentos das } \\
\text { atividades econômicas } \\
\text { (CEIS) }\end{array}$} & \multicolumn{6}{|c|}{2004} & \multicolumn{6}{|c|}{2011} \\
\hline & Norte & Nordeste & Sudeste & Sul & Centro-Oeste & Brasil & Norte & Nordeste & Sudeste & Sul & Centro-Oeste & Brasil \\
\hline Serviços de saúde & 4,5 & 17,9 & 54,2 & 16,6 & 6,8 & 100,0 & 6,2 & 20,7 & 50,8 & 14,7 & 7,7 & 100,0 \\
\hline Indústria & 6,9 & 18,5 & 56,7 & 12,1 & 5,8 & 100,0 & 3,0 & 21,6 & 59,7 & 9,8 & 5,8 & 100,0 \\
\hline Outros serviços & 9,9 & 28,6 & 39,4 & 13,6 & 8,5 & 100,0 & 7,2 & 24,5 & 43,3 & 15,7 & 9,4 & 100,0 \\
\hline Total (CEIS) & 5,5 & 19,7 & 51,7 & 16,0 & 7,1 & 100,0 & 6,3 & 21,3 & 49,7 & 14,8 & 7,9 & 100,0 \\
\hline \multirow{2}{*}{$\begin{array}{c}\text { Agrupamentos das } \\
\text { atividades econômicas } \\
\text { (CEIS) }\end{array}$} & \multicolumn{6}{|c|}{2014} & \multicolumn{6}{|c|}{2015} \\
\hline & Norte & Nordeste & Sudeste & Sul & Centro-Oeste & Brasil & Norte & Nordeste & Sudeste & Sul & Centro-Oeste & Brasil \\
\hline Serviços de saúde & 6,3 & 20,9 & 50,3 & 14,8 & 7,6 & 100,0 & 6,0 & 20,4 & 51,0 & 14,6 & 7,9 & 100,0 \\
\hline Indústria & 5,3 & 16,3 & 55,7 & 13,4 & 9,3 & 100,0 & 1,7 & 20,0 & 58,6 & 15,0 & 4,6 & 100,0 \\
\hline Outros serviços & 7,5 & 23,5 & 41,3 & 18,0 & 9,7 & 100,0 & 7,0 & 24,6 & 43,0 & 15,8 & 9,7 & 100,0 \\
\hline Total (CEIS) & 6,5 & 21,3 & 49,0 & 15,3 & 7,9 & 100,0 & 6,1 & 21,0 & 50,0 & 14,8 & 8,1 & 100,0 \\
\hline
\end{tabular}

Fonte: IBGE - PNAD. Elaboração própria (2019)

Entre 2004 e 2015, a região Centro-oeste foi a que apresentou maior aumento proporcional de trabalhadores da saúde: $74 \%$. Em seguida as regiões Norte (70\%), Nordeste (62\%), Sudeste (47\%) e Sul (41\%). O crescimento do número de trabalhadores da saúde das regiões Norte e Nordeste acima do da região Sudeste é um bom sinal, pois indica que essas regiões estão conseguindo atrair e fixar trabalhadores do complexo da saúde. No entanto, trata-se de indicadores ainda muito tímidos para alterar de forma mais significativa a histórica concentração de trabalhadores da saúde nas regiões mais ricas e urbanizadas do país.

É interessante ressaltar o alto nível de concentração das atividades industriais do complexo da saúde e de seus respectivos trabalhadores na região Sudeste. Em todos os anos, o percentual de funcionários industriais na região Sudeste, em comparação com as outras regiões, chega a ser maior do que o percentual de trabalhadores nos serviços de saúde e no próprio complexo como um todo na região. Isso evidencia a necessidade de combinar as políticas industriais voltadas para o complexo da saúde com políticas regionais que busquem descentralizar essas atividades, gerando escala e riqueza e, principalmente, spillovers para os serviços de saúde em outras partes do território nacional.

Após a descrição dos componentes do mercado de trabalho do complexo da saúde e da análise das especificidades da distribuição destes trabalhadores por natureza jurídica e pelo território brasileiro, propõem-se algumas inferências sobre as relações de trabalho presentes no CEIS. A grande maioria dos trabalhadores do complexo da saúde contribui para a previdência, sendo este um fato bastante positivo, já que para muitos autores o nível de formalização do mercado de trabalho está relacionado justamente ao vínculo dos trabalhadores com a previdência.

A tabela 6 evidencia o elevado percentual de contribuintes do CEIS, que saltou de $82,9 \%$ em 2004 para 89,9\% em 2015. Em 2011 esse percentual já estava em 89,3\%, evidenciando que a força de trabalho em saúde acompanhou o momento favorável experimentado pela economia e pelo mercado de trabalho brasileiro neste período. No ano de 2014 o índice de contribuição apresentou ligeira queda, para $88,7 \%$, e, em 2015 , voltou a subir. 
O segmento de "serviços de saúde" se destaca, por apresentar crescimento total da força de trabalho ocupada e do número de contribuintes para todos os anos analisados. Os "outros serviços de saúde" apresentaram percentuais de contribuição acima de $85 \%$ para todos os anos analisados. Já a "indústria" foi o segmento com menores percentuais de contribuintes para todos os anos analisados. Em 2004, apenas 53,6\% dos profissionais de saúde que atuavam nas indústrias médicas recolhiam para a previdência. Mas, cabe destacar que ao longo de todo o período analisado, o percentual de não contribuintes do segmento industrial diminuiu quase pela metade, passando de 46,4\% em 2004 para $29,5 \%$ em 2015. De toda forma, os dados demonstram que a referência de emprego formal para a força de trabalho em saúde está nos serviços e não na indústria, ao contrário do que ocorre no mercado de trabalho em geral, onde a indústria tende a ser o segmento mais formalizado.

Tabela 6 - Distribuição percentual da força de trabalho em saúde segundo o critério de contribuição para instituto da previdência 2004/2011/2014/2015

\begin{tabular}{|c|c|c|c|c|c|c|}
\hline \multirow{2}{*}{$\begin{array}{l}\text { Agrupamentos das } \\
\text { atividades econômicas } \\
\text { (CEIS) }\end{array}$} & \multicolumn{3}{|c|}{2004} & \multicolumn{3}{|c|}{2011} \\
\hline & Contribuinte $(\%)$ & Não contribuinte $(\%)$ & Total & Contribuinte (\%) & Não contribuinte (\%) & Total \\
\hline Serviços de saúde & 82,8 & 17,2 & 100,0 & 88,6 & 11,4 & 100,0 \\
\hline Indústria & 53,6 & 46,4 & 100,0 & 71,9 & 28,1 & 100,0 \\
\hline Outros serviços & 85,9 & 14,1 & 100,0 & 93,9 & 6,1 & 100,0 \\
\hline Total (CEIS) & 82,9 & 17,1 & 100,0 & 89,3 & 10,7 & 100,0 \\
\hline \multirow{2}{*}{$\begin{array}{c}\text { Agrupamentos das } \\
\text { atividades econômicas } \\
\text { (CEIS) }\end{array}$} & \multicolumn{3}{|c|}{2014} & \multicolumn{3}{|c|}{2015} \\
\hline & Contribuinte $(\%)$ & Não contribuinte $(\%)$ & Total & Contribuinte (\%) & Não contribuinte (\%) & Total \\
\hline Serviços de saúde & 88,7 & 11,3 & 100,0 & 89,9 & 10,1 & 100,0 \\
\hline Indústria & 67,3 & 32,7 & 100,0 & 70,5 & 29,5 & 100,0 \\
\hline Outros serviços & 89,9 & 10,1 & 100,0 & 91,6 & 8,4 & 100,0 \\
\hline Total (CEIS) & 88,7 & 11,3 & 100,0 & 89,9 & 10,1 & 100,0 \\
\hline
\end{tabular}

Fonte: IBGE - PNAD. Elaboração própria (2019)

A Tabela 7 descreve como a força de trabalho em saúde está distribuída em termos de posição na ocupação. A maioria dos trabalhadores exerce função com carteira de trabalho assinada. O percentual correspondente era de 43,5\% em 2004, aumentando para um valor em torno de 46\% nos anos de 2011, 2014 e 2015. Em seguida estão os funcionários públicos estatutários, que eram $27 \%$ do total da força de trabalho em 2015, percentual também maior do que o verificado em 2004, de 23,5\%. Entre 2004 e 2011 o crescimento dos estatutários foi significativo, com o percentual chegando a atingir $27,2 \%$ do total de trabalhadores neste último ano. Em 2014, o percentual de estatutários ficou em 25,3\%, para novamente aumentar para $27 \%$ em 2015.

Os trabalhadores sem carteira de trabalho assinada eram 14,8\% do total em 2015. Sua dinâmica apresentou variações significativas ao longo do período analisado. Entre 2004 e 2011, o percentual de trabalhadores nesta condição caiu de $18,7 \%$ para $15,6 \%$, refletindo o bom momento da economia e do mercado de trabalho. Já entre 2011 e 2014, a situação se inverteu, e o percentual dos sem carteira aumentou para 16,9\%. De 2014 para 2015, momento de instalação da crise, o percentual dos sem carteira surpreendentemente diminuiu.

Os conta própria correspondiam a $8 \%$ da força de trabalho em saúde em 2015 , valor um pouco acima do verificado em 2004, equivalente a 8,5\%. Em 2011 e 2014 o percentual manteve-se um pouco abaixo, em 7,5\%.

Aqui cabe uma observação em relação aos trabalhadores assalariados e por conta própria da força de trabalho em saúde. As informações descritas acima demonstram que em períodos de crescimento econômico, a tendência é de que o mercado de trabalho absorva mais mão-de-obra assalariada (CLT e estatutários), havendo um crescimento proporcionalmente menor dos trabalhadores por conta própria. As taxas de crescimento médio anual dos trabalhadores da saúde por posição na ocupação reforçam essa evidência. Entre 2004 e 2011, as taxas de crescimento médio anual dos empregados com carteira assinada, dos estatutários e dos conta própria foram, respectivamente, de 4,2\% a.a., 5,4\% a.a., e 1,3\% 
a.a., enquanto a do total da força de trabalho em saúde foi de 3,2\% a.a.. Já de 2014 para 2015, enquanto a força de trabalho em saúde aumentou 4,1\%, os conta própria aumentaram em 11,7\%, demonstrando que, nas crises, os trabalhadores por conta própria voltam a ganhar espaço no mercado de trabalho em saúde.

\section{Tabela 7 - Distribuição percentual da força de trabalho em saúde segundo posição na ocupação} 2004/2011/2014/2015

\begin{tabular}{|c|c|c|c|c|c|c|c|c|}
\hline \multirow{2}{*}{ Posição na ocupação } & \multicolumn{4}{|c|}{2004} & \multicolumn{4}{|c|}{2011} \\
\hline & Serviços de saúde & Indústria & Outros serviços & Total (CEIS) & Serviços de saúde & Indústria & Outros serviços & Total (CEIS) \\
\hline Empregado com carteira de trabalho assinada & 47,1 & 30,7 & 27,2 & 43,5 & 50,1 & 38,9 & 29,3 & 46,5 \\
\hline Funcionário público estatutário & 20,8 & 0,0 & 38,6 & 23,5 & 23,3 & 3,1 & 48,4 & 27,2 \\
\hline Empregado sem carteira de trabalho assinada & 15,9 & 14,9 & 32,7 & 18,7 & 14,8 & 11,2 & 20,0 & 15,6 \\
\hline Conta própria & 9,6 & 42,9 & 0,4 & 8,5 & 8,2 & 42,5 & 1,5 & 7,5 \\
\hline Empregador & 4,8 & 9,0 & 0,5 & 4,2 & 2,6 & 4,3 & 0,6 & 2,3 \\
\hline Não-remunerado & 1,8 & 2,5 & 0,6 & 1,6 & 1,0 & 0,0 & 0,2 & 0,9 \\
\hline Total & 100,0 & 100,0 & 100,0 & 100,0 & 100,0 & 100,0 & 100,0 & 100,0 \\
\hline \multirow{2}{*}{ Posição na ocupação } & \multicolumn{4}{|c|}{2014} & \multicolumn{4}{|c|}{2015} \\
\hline & Serviços de saúde & Indústria & Outros serviços & Total(CEIS) & Serviços de saúde & Indústria & Outros serviços & Total (CEIS) \\
\hline Empregado com carteira de trabalho assinada & 49,7 & 37,1 & 25,9 & 46,1 & 49,5 & 47,6 & 26,2 & 46,4 \\
\hline Funcionário público estatutário & 21,9 & 0,0 & 46,2 & 25,3 & 24,1 & 0,0 & 48,0 & 27,0 \\
\hline Empregado sem carteira de trabalho assinada & 15,5 & 7,8 & 25,8 & 16,9 & 13,5 & 4,3 & 23,5 & 14,8 \\
\hline Conta própria & 8,3 & 49,7 & 0,8 & 7,5 & 8,8 & 38,5 & 0,9 & 8,0 \\
\hline Empregador & 3,7 & 5,4 & 0,5 & 3,2 & 3,4 & 7,9 & 1,2 & 3,1 \\
\hline Não-remunerado & 1,0 & 0,0 & 0,9 & 1,0 & 0,7 & 1,7 & 0,3 & 0,6 \\
\hline Total & 100,0 & 100,0 & 100,0 & 100,0 & 100,0 & 100,0 & 100,0 & 100,0 \\
\hline
\end{tabular}

Por último está o total de empregadores, equivalente a $3,1 \%$ da força de trabalho em saúde em 2015. O total de empregadores diminuiu de forma significativa entre 2004 e 2011, com o percentual passando de 4,2\% para 2,3\%. Em seguida, voltou a aumentar, atingindo 3,2\% e 3,1\% em 2014 e 2015 , respectivamente. De toda forma, são percentuais marginais, em comparação com as outras formas de ocupação predominantes.

Entre os trabalhadores do segmento de "serviços de saúde" predominam os empregos com carteira de trabalho assinada, correspondentes a 49,5\% do total em 2015. Destaca-se que ao longo do período analisado, o total de trabalhadores deste segmento nestas condições aumentou em $68,32 \%$.

Os funcionários públicos estatutários aparecem em segundo lugar, com $24,1 \%$ dos trabalhadores dos "serviços de saúde" em 2015, e também apresentaram grande crescimento entre 2004 e 2015, de $85,07 \%$. Os empregados sem carteira assinada totalizavam 13,5\% do total em 2015, apresentando tendência de queda.

No segmento da "indústria", a maioria dos postos de trabalho também são com carteira de trabalho assinada, com um percentual equivalente a 47,6\% do total de trabalhadores em 2015. No entanto, houve uma inversão ao longo do período analisado. Em 2004, a maioria dos trabalhadores da "indústria" era conta própria (42,9\% do total). Em 2011, esse percentual correspondia praticamente ao mesmo de 2004 (42,5\%). Já em 2014, o percentual dos conta própria chegou a atingir 49,7\% do total. Entre 2014 e 2015, ocorreu o contrário, com o percentual caindo para 38,5\% do total, abaixo do percentual de trabalhadores com carteira de trabalho assinada.

Houve queda significativa do percentual de empregadores da indústria no período entre $2004 \mathrm{e}$ 2011, que passou de $9 \%$ para 4,3\%. Nos períodos seguintes, inverteu-se a lógica e houve aumento da proporção de empregadores, correspondendo a 5,4\% da força de trabalho em 2014 e 7,9\% em 2015.

Também houve queda significativa do percentual de profissionais da "indústria" sem carteira assinada em todos os anos analisados, sendo que de 2004 para 2015, os percentuais passaram de 14,9\% para $4,3 \%$.

A diminuição do percentual de profissionais que atuam na indústria sem carteira assinada acompanhada pelo crescimento da participação dos formais é um fato extremamente positivo. Por outro lado, nota-se que a participação dos estatutários no segmento industrial ainda é insignificante para todos os anos analisados, sendo possível afirmar, portanto, que, na área da saúde, a carreira típica de servidores praticamente não existe no setor industrial.

No segmento de "outros serviços de saúde", onde constam atividades de oferta pública de serviços de saúde, como os programas comunitários, a maioria dos trabalhadores era estatutária em todos 
os anos pesquisados, com percentual de $48 \%$ em 2015. Destaca-se o aumento expressivo deste percentual entre 2004 e 2011 , de $38,6 \%$ para $48,4 \%$.

O percentual de trabalhadores sem carteira assinada neste segmento é significativo, atingindo $23,5 \%$ em 2015. O percentual chegou a ser ainda maior em 2004, de 32,7\%, superando o total de trabalhadores com carteira, que correspondiam a 27,2\%. Entre 2004 e 2011 houve queda do percentual dos sem carteira neste segmento, que passaram a corresponder a $20 \%$ do total. Em seguida, até 2014, houve novo aumento, com o percentual passando para 25,8\%. E, entre 2014 e 2015, nova queda, fechando com os $23,5 \%$ de 2015.

Ainda neste segmento, os percentuais dos conta própria e empregadores são insignificantes, no entanto, destaca-se o aumento significativo do percentual dos primeiros entre 2004 e 2011, que passou de $0,4 \%$ para $1,5 \%$ do total ${ }^{3}$.

Os dados das tabelas descritas acima sugerem, portanto, que o mercado de trabalho do complexo da saúde é constituído, em sua grande maioria, por trabalhadores formais, e que esse percentual cresceu bastante, especialmente no período de pleno emprego vivenciado pela economia brasileira.

No entanto, o bom desempenho desses indicadores deve ser analisado com muita cautela. A análise geral evidencia que a maioria da força de trabalho em saúde está no setor público, mas os vínculos que predominam são de celetistas, o que demonstra as dificuldades do setor público de ofertar carreiras estáveis, típicas do setor. Além disso, o complexo é formado por um grupo de trabalhadores bastante heterogêneo, com diferenças significativas em termos de organização e relações de trabalho.

\section{Conclusões}

A discussão sobre o complexo econômico industrial da saúde tem ganhado cada vez mais relevância, já que a dinâmica do setor saúde está intrinsicamente relacionada à grande acumulação de capital e aos fluxos de inovação que ocorrem no setor. Um componente importante deste complexo, que ainda é pouco estudado na literatura nacional, é sua força de trabalho. O complexo da saúde constitui-se como um setor com grande capacidade de geração de emprego e renda. Além disso, os trabalhadores presentes neste segmento são essenciais, não só para a garantia da oferta de serviços de saúde, como também no processo de geração e incorporação de novas tecnologias.

A análise dos dados relacionados ao conjunto da força de trabalho presente no complexo da saúde brasileiro realizada neste artigo evidenciou que este segmento mantém significativo dinamismo em termos de crescimento, participação na economia e capacidade de absorver mão-de-obra, sendo puxado, principalmente, pela atuação dos serviços de saúde do setor público. Por outro lado, há evidências de pouca participação das indústrias do complexo na empregabilidade de profissionais e na geração de produtos e equipamentos, principalmente fora da região Sudeste, a qual concentra territorialmente os trabalhadores do complexo. Essa tímida atuação das atividades industriais tradicionais na área da saúde no Brasil mostra-se problemática, especialmente no contexto atual, onde novos paradigmas econômicos têm assumido papel estratégico na articulação dos sistemas de saúde dos países capitalistas desenvolvidos, como a nanotecnologia, o setor de informática e telecomunicações e a Inteligência Artificial.

Os dados também mostram que o setor público ainda é o principal empregador do total da força de trabalho em saúde e que a maioria desses trabalhadores exerce suas atividades com carteira assinada. Mas, não se pode deixar de ressaltar o avanço do setor privado na empregabilidade destes trabalhadores nos últimos anos.

Dessa forma, o esforço que o país precisa realizar para lidar com todos esses desafios é de escala sem precedentes. É preciso articular políticas públicas que sejam capazes de impactar a qualidade e a distribuição espacial do trabalho em saúde, além de garantir círculos virtuosos entre produção de insumos e tecnologias em saúde e atendimento da saúde da população. É necessário, inclusive, que o atual desenho do complexo da saúde no país seja expandido, de forma a contemplar a participação de

\footnotetext{
${ }^{3}$ Ressalta-se que apesar desse aumento expressivo, no cômputo de todo o CEIS a participação dos conta própria diminuiu entre 2004 e 2011, conforme já ressaltado anteriormente.
} 
novos setores econômicos que se tornaram essenciais para o desenvolvimento de inovações, tanto em forma de produtos, como de processos, e também para a criação de empregos e geração de renda.

\section{Workforce in the health economic-industrial complex in Brazil: some evidences}

Abstract: This paper aimed to analyze the main characteristics of the health workforce in Brazil from the perspective of the health economic-industrial complex (CEIS). This perspective of analysis of the health sector encompasses both the institutions responsible for the provision of health services and the industries that produce medical technologies, corroborating the view that the health sector can contribute both to the wellbeing of the population and to economic development, from the generation of income, employment and technological innovations. Studies on this theme are relevant since Brazil has, in a strategic way, a great potential for scientific production in the health area, which is currently underutilized by the medical industries. In addition, the country has a public and universal health system with a large capacity for absorbing labor. In this way, the health complex is configured as a window of opportunity for the development of the country, and it is necessary to understand the structural and political difficulties faced for its construction. Therefore, focusing on the workforce of the health complex, this study sought to estimate the size of this workforce and some particularities of their work relationships. The information was taken from the PNAD-IBGE database for the years 2004, 2011, 2014 and 2015, respectively. The choice of these specific years was motivated by the attempt to measure the dynamics of the health workforce in the scenario of economic growth, investment and stability that characterized the country's economy until 2015. The study revealed the growing importance of the health complex for job creation in the country in recent years, but with some peculiarities. We highlight the weight of the public sector in the hiring of these workers, the concentration of this workforce in the Southeast region and the low participation of the medical industries in the employability of these professionals, in comparison with the service sector. It was concluded that there is a need for the elaboration of policies that contemplate this workforce and strengthen the construction of CEIS, since this economic segment constitutes an important strategy for the development of welfare and innovation systems in Brazil.

Keywords: health economic-industrial complex; health workforce; Brazil 


\section{Referências Bibliográficas}

ALBUQUERQUE, Eduardo; CASSIOLATO, José Eduardo. As especificidades do sistema de inovação do setor saúde: uma resenha da literatura como introdução a uma discussão sobre o caso brasileiro, FeSBE. São Paulo: 2000 (Estudos FeSBE I).

COSTA, Laís; BAHIA, Lígia. Inovação nos serviços de saúde: geração e trajetórias, in: Saúde Amanhã, Fundação Oswaldo Cruz. Rio de Janeiro: 2015 (Textos para discussão no 9).

COSTA, Laís; GADELHA, Carlos Augusto; BORGES, Taís; BURD, Paula; MALDONADO, José; VARGAS, Marco. A dinâmica inovativa para a reestruturação dos serviços de saúde, in: Revista de Saúde Pública, vol. 46 (supl. 1). São Paulo: 2012.

COSTA, Laís; GADELHA, Carlos Augusto; MALDONADO, José; VARGAS, Marco; QUENTAL, Cristiane. Análise do subsistema de serviços em saúde na dinâmica do complexo econômico-industrial da saúde, in: A saúde no Brasil em 2030 - prospecção estratégica do sistema de saúde brasileiro: desenvolvimento produtivo e complexo da saúde, v. 5, Fundação Oswaldo Cruz. Rio de Janeiro: 2013.

DEDECCA, Cláudio. O trabalho no setor saúde, in: São Paulo em Perspectiva, v.22, n.2, p.87-103, 2008.

DEDECCA, Cláudio; TROVÃO, Cassiano. A força de trabalho no complexo da saúde: vantagens e desafios, in: Ciência e Saúde Coletiva, v.18, n.6, p.555-1567. Rio de Janeiro: 2013.

GADELHA, Carlos Augusto. O complexo industrial da saúde e a necessidade de um enfoque dinâmico na economia da saúde, in: Ciência e saúde coletiva, v. 8, n.2, p. 521-535, Rio de Janeiro: 2003.

GADELHA, Carlos Augusto. Desenvolvimento, complexo industrial da saúde e política industrial, in: Revista de Saúde Pública, v. 40, p. 11-23. São Paulo: 2006.

GADELHA, Carlos Augusto (coord.). A dinâmica do sistema produtivo da saúde: inovação e complexo econômico-industrial, Fundação Oswaldo Cruz. Rio de Janeiro: 2012.

GADELHA, Carlos Augusto; BRAGA, Patrícia. Saúde e inovação: dinâmica econômica e Estado de BemEstar Social no Brasil, in: Cadernos de Saúde Pública, v. 32 (supl. 2). Rio de Janeiro: 2016.

GADELHA, Carlos Augusto; COSTA, Laís; MALDONADO, José. O complexo econômico-industrial da saúde e a dimensão social e econômica do desenvolvimento, in: Revista de Saúde Pública, n. 46 (supl.). São Paulo: 2012.

GADELHA, Carlos Augusto; QUENTAL, Cristiane; FIALHO, Beatriz. Saúde e inovação: uma abordagem sistêmica das indústrias da saúde, in: Cadernos de Saúde Pública, v. 19, n.1, Rio de Janeiro: 2003.

GADELHA, Carlos Augusto; TEMPORÃO, José. Desenvolvimento, inovação e saúde: a perspectiva teórica e política do Complexo Econômico-Industrial da Saúde, in: Ciência e saúde coletiva, v. 23, n. 6, p.1891-1902, Rio de Janeiro: 2018.

GIRARDI, Sábado; CARVALHO, Cristiana. Contratação e qualidade do emprego no Programa de Saúde da Família no Brasil, in: Ministério da Saúde (org.), Observatório de Recursos Humanos em Saúde no Brasil: estudos e análises, Editora Fiocruz. Rio de Janeiro: 2003.

GIRARDI, Sábado; MAAS, Lucas (orgs.). Informações sobre o mercado de trabalho em saúde: conceitos, bases de dados e indicadores. Estação de Pesquisa de Sinais de Mercado de Trabalho. NESCON/UFMG. Belo Horizonte: 2013. 
INSTITUTO BRASILEIRO DE GEOGRAFIA E ESTATÍSTICA - IBGE: Classificação Brasileira de Ocupações (CBO Domiciliar), consultado em 2019.

INSTITUTO BRASILEIRO DE GEOGRAFIA E ESTATÍSTICA - IBGE: Classificação Nacional das Atividades Econômicas (CNAE Domiciliar), consultado em 2019.

INSTITUTO BRASILEIRO DE GEOGRAFIA E ESTATÍSTICA - IBGE: Conta Satélite de Saúde, consultado em 2019.

INSTITUTO BRASILEIRO DE GEOGRAFIA E ESTATÍSTICA - IBGE: Microdados da Pesquisa Nacional por Amostra de Domicílios (Pnad), consultado em 2019.

NOGUEIRA, Roberto. A força de trabalho em saúde, in: Revista de Administração Pública, v.17, n.3, p.61-70, jul./set. Rio de Janeiro: 1983.

NOGUEIRA, Roberto; GIRARDI, Sábado. O perfil do emprego na Função Saúde. Instituto de Pesquisa Econômica Aplicada (mimeo). Brasília: 1999.

SCHUMPETER, Joseph. Capitalismo, Socialismo, Democracia. Londres: 1976. 